УДК 340.131 .5

DOI: $10.35750 / 2071-8284-2020-3-61-65$

\author{
Е. Е. Новопавловская \\ кандидат юридических наук, доцент \\ Белгородский государственный технологический университет им. В. Г. Шухова \\ Российская Федераиия, 308012, Белгород, ул. Костюкова, д. 46 \\ ORCID: 0000-0002-5103-1427. E-mail: novopavlovskayae@gmail.com

\section{Деятельность Конституционного Суда Российской Федерации в период пандемии COVID-19}

\begin{abstract}
Аннотация: Даже в период пандемии коронавируса (COVID-19) все суды, в том числе Конституционный Суд Российской Федерации, осуществляли свою деятельность. Однако формат их функционирования стал иным, нежели прежде. Условия пандемии коронавируса (COVID-19) заставили многих перейти в иной формат работы, побудили ускорить процессы цифровизации, в том числе реализацию основных этапов цифровизации правосудия, включающих предоставление в электронном виде общего доступа к актам судебных органов, замену протоколов в бумажном виде аудиопротоколами, налаживание удобного электронного документооборота, а также устойчивой и доступной системы видеоконференцсвязи в судах, формирование доступного и удобного отслеживания задержек в проведении судебных заседаний и принятых судебных актов и др. В статье проведён мониторинг практики судебного конституционного нормоконтроя в период пандемии коронавируса, сделан акцент на исследовании сущности спорных правоотношений. На основе полученных результатов автор приходит к выводу о том, что даже в нетипичных, сложных для всей страны и мира в целом условиях, граждане и их объединения высказывали неудовлетворённость регламентацией отношений различной отраслевой принадлежности, призывая Конституционный Суд Российской Федерации вывести из правового пространства неконституционные нормы, устранить проблемы правотворческого характера, выступающие причинами проблем правоприменительной практики.

Ключевые слова: цифровизация правосудия, пандемия, Конституционный Суд, нормоконтроль, правовая неопределённость.
\end{abstract}

Для иитирования: Новопавловская Е. Е. Деятельность Конституционного Суда Российской Федерации в период пандемии COVID-19 // Вестник Санкт-Петербургского университета МВД России. - 2020. - № 3 (87). - С. 61-65. DOI: 10.35750/2071-8284-2020-3-61-65.

Elena E. Novopavlovskaya

Cand. Sci. (Jurid.), Docent

Belgorod State Technological University named after V.G. Shukhov

46, Kostyukov str., Belgorod, 308012, Russian Federation

ORCID: 0000-0002-5103-1427. E-mail: novopavlovskayae@gmail.com

\title{
Activities of the Constitutional Court of the Russian Federation during the COVID-19 pandemic
}

\begin{abstract}
Annotation: Even during the coronavirus pandemic (COVID-19) all courts including the Constitutional Court of the Russian Federation carried out their activities. However, the format of their functioning has become different than before. The conditions of the coronavirus pandemic (COVID-19) forced a great deal of organisations to pass to a different operating mode, encouraged them to speed up digitalization processes, including the implementation of the main stages of digitalization of justice, comprising the provision of electronic access to judicial acts, the replacement of paper-based protocols with audio protocols, the regulation of convenient electronic document flow as well as a stable and accessible video conferencing system in courts, the formation of an accessible and convenient system of tracking delays of court hearings and adopted judicial acts, etc. The article gives the monitoring results of the practice of judicial constitutional regulation during
\end{abstract}


the coronavirus pandemic, emphasizes the study of the essence of controversial legal relations. Based on the results obtained, the author comes to the conclusion that even in atypical, difficult conditions for the whole country and the entire world, citizens and their associations expressed dissatisfaction with the regulation of relations of various industry branches, urging the Constitutional Court of the Russian Federation to remove unconstitutional norms from the legal space, to eliminate problems of a law-making nature, which are the causes of problems of law enforcement practice.

Keywords: digitalization of justice, pandemic, Constitutional Court, rule of law, legal ambivalence.

For citation: Novopavlovskaya E. E. Activities of the Constitutional Court of the Russian Federation during the COVID-19 pandemic // Vestnik of St. Petersburg University of the Ministry of Internal Affairs of Russia. - 2020. - № 3 (87). - P. 61-65. DOI: 10.35750/2071-8284-2020-3-61-65.

Реалии пандемии коронавируса (COVID-19) заставили многих из нас перейти в иной формат работы, в том числе дистанционный. Не осталась в стороне и судебная власть. Особую актуальность и значимость в таких условиях приобрели вопросы востребованности электронных ресурсов судебной системы и цифровизации правосудия в целом, которые уже не один год вызывают как научный, так и практический интерес исследователей, оценивающих положительные и отрицательные аспекты применения нейронной сети в целях обеспечения особого формата юридического взаимодействия судебной власти и общества $[1$, c. $50-56 ; 2$, c. $23-25 ; 3 ; 4$, с. $46-49 ; 5 ; 6$, с. $26-31 ; 7$, c. 11-18].

Принятые в разные годы нормативные правовые акты ${ }^{1}$, направленные на развитие российской судебной системы, в том числе документы программного характера, зафиксировали мероприятия по информатизации и внедрению современных информационных технологий, включая автоматизированные системы (в частности, ГАС «Правосудие» ${ }^{2}$, призванные минимизировать нарушение процессуальных сроков, сократить количество незавершённых дел, обеспечить удобную и быструю доступность к информации, повысив тем самым качество и доступность правосудия ${ }^{3}$. Однако согласимся с

${ }^{1}$ Об обеспечении доступа к информации о деятельности судов в Российской Федерации : Федеральный закон от 22 декабря 2008 г. № 262-Ф3 (в ред. от 28 декабря 2017 г.) // Собрание законодательства Российской Федерации. - 2008. - № 52 (ч. 1). - Ст. 6217; О внесении изменений в отдельные законодательные акты Российской Федерации в части применения электронных документов в деятельности органов судебной власти : Федеральный закон от 23 июня 2016 г. № 220-Ф3 // Собрание законодательства Российской Федерации. - 2016. - № 26 (часть I). - Ст. 3889.

${ }^{2}$ Государственная автоматизированная система Российской Федерации «Правосудие». - URL.: https://sudrf.ru/

${ }^{3} \mathrm{O}$ федеральной целевой программе «Развитие судебной системы России на 2007-2012 годы» : Постановление Правительства Российской Федерации от 21 сентября 2006 г. № 583 (в ред. от 1 ноября 2012 г.) // Собрание законодательства Российской Федерации. - 2006. - № 41. - Ст. 4248; О федеральной целевой программе «Развитие судебной системы России на 2013-2020 годы» : Постановление Правительства Российской Федерации от 27 декабря 2012 г. № 1406 (в ред. от 25 декабря 2019 г.) // Собрание законодательства Российской Федерации. - 2013. - № 1. - Ст. 13. мнением К. Л. Брановицкого, что умелое использование современных технологий в правосудии приведёт к значительному сокращению или облегчению «пути к судебной защите», но не решит всех проблем его качества и доступности. Подобного рода проблемы требуют применения комплексного подхода, «целевые индикаторы и показатели по которому легче в достижении» $[8$, c. 4]. Сюда относится направление процессуальных документов в электронном виде; использование автоматизированных систем распределения дел между судьями, что позволяет компьютерно формировать судебные составы, учитывая нагрузку и специализацию судей; увеличение числа залов судебных заседаний, оборудование которых позволяет проводить видеопротоколирование; расширение иных возможностей электронного взаимодействия судов и общества. Как справедливо замечает Ю. С. Харитонова, в числе мер по цифровизации правосудия в России должны быть и такие, которые призваны обеспечивать безопасность информации, хранящейся в системах судов $[9$, с. 3]. Факт необходимости обеспечения информационной безопасности и защиты информации, а также поиска баланса между правом на неприкосновенность частной жизни и защиту персональных данных, с одной стороны, и правом на доступ к информации о деятельности суда, с другой, также верно подчёркивают Е. В. Гриценко и Ю. А. Ялунер [10, с. 98].

Сложившиеся условия пандемии потребовали осуществления корректировки деятельности всей судебной власти, при которой должен был соблюдаться баланс обеспечения безопасности здоровья, жизни граждан и принципа доступности правосудия. Президиумом Верховного суда Российской Федерации и Президиумом Совета судей Российской Федерации были даны соответствующие рекомендации судам о порядке их дальнейшей деятельности в сложившихся условия ${ }^{4}$, с соблюдением которых чуть более

${ }^{4} \mathrm{O}$ приостановлении личного приёма граждан в судах : Постановление Президиума Верховного Суда Российской Федерации, Президиума Совета судей Российской Федерации от 18 марта 2020 г. № 808; О приостановлении 
чем за один месяц было рассмотрено свыше 2 млн дел и материалов 5 .

Весьма активно в период пандемии COVID-19 осуществлял свою деятельность и Конституционный Суд Российской Федерации ${ }^{6}$ мониторинг практики которого позволяет сделать следующие выводы.

Во-первых, решения КС РФ были приняты не только по обращениям, поступившим в период пандемии, но и до его начала. На официальном сайте КС РФ в разделе «Обращения в КС РФ» появилась новая вкладка «Электронная система подачи обращений» ${ }^{7}$, пройдя по которой, заявитель попадает в личный кабинет. Признаем, что в сложившихся реалиях пандемии граждане и их объединения активно используют подобное нововведение.

Во-вторых, в качестве заявителей выступали как отдельные граждане: индивидуально (Постановление КС РФ от 25 июня 2020 г. № 29-П ${ }^{8}$ ) либо коллективно (Постановление КС РФ от 24 марта 2020 г. № 12-П9 ${ }^{9}$ Постановление КС РФ от 26 июня 2020 г. № $\left.30-\Pi^{10}\right)$, так и юридические лица различных организационноправовых форм, в том числе ООО (Постановление КС РФ от 21 апреля 2020 г. № 19-П ${ }^{11}$, Постановление КС РФ от 12 мая 2020 г. № 23-П ${ }^{12}$ ), AO (Постановление Конституционного Суда РФ от 7 апреля 2020 г. № $15-\Pi^{13}$, Постановление КС РФ от 30 июня 2020 г. № 31-П $\left.{ }^{14}\right)$ и др. Более того, имели место также обращения представителей властных структур государства, например, законодательных (представительных) органов государственной власти (Постановление КС РФ от 4 июня 2020 г. № 27-П ${ }^{15}$ ), судов (Определение

личного приёма граждан в судах : Постановление Президиума Верховного Суда Российской Федерации, Президиума Совета судей Российской Федерации от 08 апреля 2020 г. № 821 // СПС «Консультант Плюс».

${ }^{5}$ Работа отечественных судов в условиях пандемии информация Верховного Суда Российской Федерации от 21 апреля 2020 г. // СПС «Консультант Плюс».

${ }^{6}$ Далее - КС РФ.

${ }^{7}$ Официальный сайт КС РФ. - URL: https://petition. ksrf.ru/ (дата обращения: 25 июля 2020).

${ }^{8}$ Собрание законодательства Российской Федерации. - 2020. - № 27. - Ст. 4287.

${ }^{9}$ Собрание законодательства Российской Федерации. - 2020. - № 15 (часть IV). - Ст. 2431.

${ }_{10}$ Собрание законодательства Российской Федерации. - 2020. - № 27. - Ст. 4288.

${ }^{11}$ Собрание законодательства Российской Федерации. - 2020. - № 20. - Ст. 3223.

${ }_{12}$ Собрание законодательства Российской Федерации. - 2020. - № 20. - Ст. 3227.

${ }^{13}$ Собрание законодательства Российской Федерации. - 2020. - № 15 (часть IV). - Ст. 2434.

${ }_{14}$ Собрание законодательства Российской Федерации. - 2020. - № 28. - Ст. 4497.

${ }^{15}$ Собрание законодательства Российской Федерации. - 2020. - № 24. - Ст. 3851.
КС РФ от 18 июня 2020 г. № 1345-Оㅜㄹ) и др. В частности, по запросу Костромского областного суда КС РФ дал оценку конституционности положений ст. 4.6 и ч. 1.3 ст. 32.2 Кодекса Российской Федерации об административных правонарушениях, признав их противоречащими Конституции Российской Федерации, поскольку они не позволяют определить порядок исчисления срока, в течение которого лица, уплатившие административный штраф в половинном размере до вступления постановления о его назначении в законную силу, считаются подвергнутыми административному наказанию. В этой связи КС РФ возложил на федерального законодателя обязанность по проведению соответствующих корректировок норм административного законодательства (Постановление КС РФ от 23 июня 2020 г. № 28-П $\left.{ }^{17}\right)$. И, следовательно, третий вывод, который мы можем сделать: КС РФ не только выводит из правового пространства неконституционные законоположения, но и участвует в механизме устранения правовых неопределённостей.

В-четвертых, предмет рассмотрения в порядке конституционного судопроизводства составляли нормативные правовые акты, регламентирующие общественные отношения различной отраслевой направленности. Речь шла не только о неконституционности норм материального права: конституционного, гражданского (Постановление КС РФ от 28 апреля 2020 г. № 21-П ${ }^{18}$, Определение КС РФ от 18 июня 2020 г. № 1345-О), трудового (Постановление КС РФ от 19 мая 2020 г. № 25-П ${ }^{19}$ ), земельного (Постановление КС РФ от 5 марта 2020 г. № $\left.11-\Pi^{20}\right)$, налогового (Постановление КС РФ от 9 апреля 2020 г. № 16-П ${ }^{21}$, Постановление КС РФ от 29 апреля 2020 г. № 22-П²2, Постановление КС РФ от 30 июня 2020 г. № 31-П), административного (Постановление КС РФ от 14 апреля 2020 г. № $17-$ $\Pi^{23}$, Постановление КС РФ от 13 мая 2020 г. № $24-\Pi^{24}$, Постановление КС РФ от 23 июня 2020 г.

${ }^{16}$ Работа отечественных судов в условиях пандемии : информация Верховного Суда Российской Федерации от 21.04.2020 // СПС «Консультант Плюс».

${ }_{17}$ Собрание законодательства Российской Федерации. - 2020. - № 27. - Ст. 4286.

${ }_{18}^{18}$ Собрание законодательства Российской Федерации. - 2020. - № 20. - Ст. 3225.

${ }^{19}$ Собрание законодательства Российской Федерации. - 2020. - № 21. - Ст. 3375.

${ }^{20}$ Собрание законодательства Российской Федерации. - 2020. - № 11. - Ст. 1639.

21 Российская газета: Федеральный выпуск. 20.04.2020. - № 85 (8139).

${ }^{22}$ Собрание законодательства Российской Федерации. - 2020. - № 20. - Ст. 3226.

${ }^{23}$ Собрание законодательства Российской Федерации. - 2020. - № 20. - Ст. 3221.

${ }^{24}$ Собрание законодательства Российской Федерации. - 2020. - № 20. - Ст. 3228. 
№ 28-П), права социального обеспечения (Постановление КС РФ от 27 мая 2020 г. № 26-П²5) и др., но и процессуального, например, гражданско-процессуального права (Постановление КС РФ от 26 июня 2020 № 30-П). Значительное количество решений КС РФ приходится на июль 2020 г. И опять-таки отраслевая направленность оспариваемых заявителями норм весьма многообразна, при этом большинство из них составляли положения кодифицированных правовых актов, в частности, Гражданского кодекса Российской Федерации (Постановление КС РФ от 24 июля 2020 № 40-П ${ }^{26}$ ), Трудового кодекса Российской Федерации (Постановление КС РФ от 14 июля 2020 г. № 35-П ${ }^{27}$ ), Налогового кодекса Российской Федерации (Постановление КС РФ от 2 июля 2020 № 32-П $\left.{ }^{28}\right)$, Уголовного кодекса Российской Федерации (Постановление КС РФ от 22 июля 2020 № 38- П ${ }^{29}$ ), Арбитражного процессуального кодекса Российской Федерации (Постановление КС РФ от 16 июля 2020 г. № 37$\left.\Pi^{30}\right)$, Уголовно-процессуального кодекса Российской Федерации (Постановление КС РФ от 7 июля 2020 г. № 33-П

Примечательно, что заявители высказывали свою неудовлетворённость законодательным регулированием различных аспектов конституционных прав граждан различной видовой принадлежности, в том числе:

- личных прав, например, свободы передвижения (Постановление Конституционного Суда РФ от 25 июня 2020 г. № 29-П);

- политических прав - в частности, права на проведение публичных массовых мероприятий (Постановление КС РФ от 4 июня 2020 г. № 27-П), права на равный доступ к государственной службе (Постановление КС РФ от 6 апреля 2020 г. № $14-\Pi^{32}$ );

- социально-экономических прав, например, права граждан на социальное обеспечение (Постановление КС РФ от 22 апреля 2020 г. № 20$\left.\Pi^{33}\right)$, что в условиях пандемии коронавируса

${ }^{25}$ Собрание законодательства Российской Федерации. - 2020. - № 22. - Ст. 3586.

26 Российская газета: Федеральный выпуск. 07.08.2020. - № 174 (8228).

27 Российская газета: Федеральный выпуск. 24.07.2020. - № 162 (8216).

28 Российская газета: Федеральный выпуск. 15.07.2020. - № 153 (8207).

29 Российская газета: Федеральный выпуск. 31.07.2020. - № 168 (8222).

30 Российская газета: Федеральный выпуск. 24.07.2020. - № 162 (8216).

31 Российская газета: Федеральный выпуск. 15.07.2020. - № 153 (8207).

32 Собрание законодательства Российской Федерации. - 2020. - № 15 (часть IV). - Ст. 2433.

${ }_{33}$ Собрание законодательства Российской Федерации. - 2020. - № 20. - Ст. 3224 приобрело особое звучание, актуальность и значимость в связи с приостановлением, а порой и прекращением деятельности ряда предприятий, учреждений и организаций, когда работодатели допускали грубые нарушения трудового законодательства, в том числе, не выплачивая либо сокращая заработную плату, осуществляя незаконные увольнения и др.

В-пятых, обратим также внимание, что нормоконтрольная функция КС РФ реализовывалась не только в отношении нормативных правовых актов федерального уровня, но и регионального. Наглядным примером тому может выступать Постановление от 4 июня 2020 г. № 27-П, в котором КС РФ констатировал неконституционность положений Закона Самарской области «О порядке подачи уведомления о проведении публичного мероприятия и обеспечении отдельных условий реализации прав граждан на проведение публичных мероприятий в Самарской области» в части установленного в ст. 3.4 запрета на проведение публичного мероприятия в месте, расположенном ближе 150 метров от военных объектов; зданий, в которых расположены образовательные учреждения; зданий и объектов, используемых для богослужений, проведения религиозных обрядов и церемоний; зданий, занимаемых организациями, предназначенными для оказания стационарной медицинской помощи. В обоснование данного решения КС РФ отметил, что подобное регулирование находится за конституционно установленными пределами законодательных полномочий субъектов Российской Федерации. Резюмируем, что речь идёт о нарушениях принципов разграничения предметов ведения и полномочий между федеральным центром и российскими регионами. И опять-таки КС РФ признал необходимость внесения соответствующих законодательных изменений в части корректировки названного выше закона Самарской области.

Приведённые данные и примеры практики КС РФ наглядно подтверждают, что даже в сложных условиях пандемии граждане и их объединения активно прибегали к механизмам конституционного судопроизводства, используя функцию судебного конституционного нормоконтроля в целях защиты своих конституционных прав и свобод. Констатируем также факт повышения востребованности электронных ресурсов судебной системы, но это вовсе не означает, что нейронные сети должны заменить судей. Нейронные сети следует рассматривать лишь как вспомогательный инструмент для анализа документов. Не более того. 


\section{Список литературь}

1. Белякова A. В. Развитие цифровых технологий в системе правосудия как один из способов ускорения судопроизводства в Российской Федерации // Арбитражный и гражданский процесс. 2019. - № 12. - С. 50-56.

2. Боброва Н. А. Цифровизация: плюсы и минусы // Конституционное и муниципальное право. - 2019. - № 10. - С. 23-25.

3. Защита данных: научно-практический комментарий к судебной практике / Э. В. Алимов, Д. Р. Алимова, Х. И. Гаджиев и др.; отв. ред. В. В. Лазарев, Х. И. Гаджиев. - Москва: ИЗиСП, Контракт, 2020. - 176 c.

4. Котлярова В. В. К вопросу о цифровизации процесса отправления правосудия // Арбитражный и гражданский процесс. - 2019. - № 12. - С. 46-49.

5. Проскурякова М. И. Защита персональных данных в праве России и Германии: конституционно-правовой аспект : автореф. дис. ... канд. юрид. наук. - Санкт-Петербург, 2017. - 26 с.

6. Саурин A. А. Цифровизация как фактор трансформации права // Конституционное и муниципальное право. - 2019. - № 8. - С. 26-31.

7. Танимов О. В. Трансформация правоотношений в условиях цифровизации // Актуальные проблемы российского права. - 2020. - № 2. - С. 11-18.

8. Брановицкий К. Л. Соотношение понятий «качество» и «цифровизация правосудия» // Арбитражный и гражданский процесс. - 2019. - № 7. - С. 3-7.

9. Харитонова Ю. С. Платформизация правосудия: опыт Китая и будущее судебных систем мира // Вестник арбитражной практики. - 2020. - № 3. - С. 3-11.

10. Гриценко Е. В., Ялунер Ю. А. Право на судебную защиту и доступ к суду в условиях информатизации и цифровизации: значение опыта стран общего права для России // Сравнительное конституционное обозрение. - 2020. - № 3. - С. 97-129.

\section{References}

1. Belyakova $A$. V. Razvitie tsifrovykh tekhnologii v sisteme pravosudiya kak odin iz sposobov uskoreniya sudoproizvodstva v Rossiiskoi Federatsii // Arbitrazhnyi i grazhdanskii protsess. - 2019. № 12. - S. 50-56.

2. Bobrova N. A. Tsifrovizatsiya: plyusy i minusy // Konstitutsionnoe i munitsipal'noe pravo. - 2019. № 10. - S. 23-25.

3. Zashchita dannykh: nauchno-prakticheskii kommentarii k sudebnoi praktike / E. V. Alimov, D. R. Alimova, Kh. I. Gadzhiev i dr.; otv. red. V. V. Lazarev, Kh. I. Gadzhiev. - Moskva: IZiSP, KONTRAKT, 2020. - $176 \mathrm{~s}$.

4. Kotlyarova V. V. K voprosu o tsifrovizatsii protsessa otpravleniya pravosudiya // Arbitrazhnyi i grazhdanskii protsess. - 2019. - № 12. - S. 46-49.

5. Proskuryakova M. I. Zashchita personal'nykh dannykh v prave Rossii i Germanii: konstitutsionnopravovoi aspekt: avtoref. dis. ... kand. yurid. nauk. - Sankt-Peterburg, 2017. - 26 s.

6. Saurin A. A. Tsifrovizatsiya kak faktor transformatsii prava // Konstitutsionnoe i munitsipal'noe pravo. - 2019. - № 8. - S. 26-31.

7. Tanimov O. V. Transformatsiya pravootnoshenii v usloviyakh tsifrovizatsii // Aktual'nye problemy rossiiskogo prava. - 2020. - № 2. - S. 11-18.

8. Branovitskii K. L. Sootnoshenie ponyatii «kachestvo» $\mathrm{i}$ «tsifrovizatsiya pravosudiya» // Arbitrazhnyi i grazhdanskii protsess. - 2019. - № 7. - S. 3-7.

9. Kharitonova Yu. S. Platformizatsiya pravosudiya: opyt Kitaya i budushchee sudebnykh sistem mira // Vestnik arbitrazhnoi praktiki. - 2020. - № 3. - S. 3-11.

10. Gritsenko E. V., Yaluner Yu. A. Pravo na sudebnuyu zashchitu i dostup k sudu v usloviyakh informatizatsii i tsifrovizatsii: znachenie opyta stran obshchego prava dlya Rossii // Sravnitel'noe konstitutsionnoe obozrenie. - 2020. - № 3. - S. 97-129.

(C) Новопавловская Е. Е., 2020

Статья поступила в редакцию 30.06.2020 г. 